\title{
Effects of antenatal corticosteroids in twin neonates with late preterm birth (ACTWIN [Antenatal Corticosteroids in TWIN late preterm neonates] trial): study protocol for a randomized controlled trial
}

Subeen Hong ${ }^{1,2+}$, Seung Mi Lee ${ }^{1 \dagger}$, Dong Wook Kwak ${ }^{3,4}$, Joongyub Lee ${ }^{5,6}$, So Yeon Kim', Jeong Won Oh', Sohee Oh${ }^{7}$, Chan-Wook Park ${ }^{1}$, Joong Shin Park', Jin Hoon Chung ${ }^{3^{*+}}$ (ID and Jong Kwan Jun ${ }^{1^{*+}}$

\begin{abstract}
Background: Antenatal corticosteroids have been proven to prevent adverse outcomes including respiratory morbidities in preterm neonates before 34 weeks of gestation. Recently, it has been suggested that antenatal corticosteroids may also be effective in singleton late preterm pregnancies, and guidelines recommend the use of corticosteroids in singleton pregnant women who are at risk for late preterm birth. On the contrary, there is a paucity of information regarding the effectiveness of corticosteroids in twin neonates with late preterm birth. This study aims to determine the effectiveness of antenatal corticosteroids in late preterm twin neonates.

Methods: In this multicentre randomized controlled trial, women who are at risk for late preterm birth will be enrolled at 34 0/7 to 36 5/7 weeks of gestation. The participants will be randomly assigned to receive antenatal corticosteroids (betamethasone $12 \mathrm{mg}, 3 \mathrm{~mL}$ intramuscularly [IM]) or placebo (normal saline $3 \mathrm{~mL} I \mathrm{IM}$ ). The perinatal outcomes will be compared between the two groups of cases. The primary outcome is severe respiratory complications (the use of continuous positive airway pressure or high-flow nasal cannula for at least $12 \mathrm{~h}$, supplemental oxygen administration with a fraction of oxygen 0.3 or more for at least $24 \mathrm{~h}$, mechanical ventilation, or extracorporeal membranes oxygenation) or perinatal death within the first $72 \mathrm{~h}$ of delivery. The secondary outcomes are neonatal mortality and/or other neonatal morbidities.
\end{abstract}

Discussion: This study will be the first randomized controlled trial that evaluates the effectiveness of antenatal corticosteroids in late preterm twin neonates.

Trial registration: NCT03547791(ClinicalTrials.gov), first submitted date: March 29, 2018, first posted date: June 6, 2018 (retrospectively registered).

Keywords: Antenatal corticosteroids, Late preterm birth, Twin pregnancies, Respiratory morbidity, Randomized controlled trial

\footnotetext{
* Correspondence: sabi0515@hanmail.net; jhs0927@snu.ac.kr

Subeen Hong and Seung Mi Lee contributed equally as the first authors of this study. Jin Hoon Chung and Jong Kwan Jun contributed equally as the corresponding authors of this study.

${ }^{3}$ Department of Obstetrics and Gynecology, Cheil General Hospital and

Women's Healthcare Center, Dankook University College of Medicine, Seoul,

South Korea

${ }^{1}$ Department of Obstetrics and Gynecology, Seoul National University

College of Medicine, Seoul, Republic of Korea

Full list of author information is available at the end of the article
}

(c) The Author(s). 2019 Open Access This article is distributed under the terms of the Creative Commons Attribution 4.0 International License (http://creativecommons.org/licenses/by/4.0/), which permits unrestricted use, distribution, and reproduction in any medium, provided you give appropriate credit to the original author(s) and the source, provide a link to the Creative Commons license, and indicate if changes were made. The Creative Commons Public Domain Dedication waiver (http://creativecommons.org/publicdomain/zero/1.0/) applies to the data made available in this article, unless otherwise stated. 


\section{Background}

The number of multifetal pregnancies has recently been increasing. Between 1980 and 2009, the frequency of twin pregnancies in the United States increased by three-fourths, from 18.9 to 33.3 per 1000 births, and this phenomenon has been attributed to advancing maternal age and increased use of assisted reproductive technique [1]. Multifetal pregnancies are at higher risk for maternal and neonatal complications compared with singleton pregnancies, and preterm birth is one of the most important issues in twin pregnancies [2-5]. Indeed, the rate of preterm birth in twin pregnancy is as high as 50\%, with most cases occurring in the late preterm period (34 $0 / 7$ to $366 / 7$ weeks of gestation) [6, 7]. Late preterm birth has recently emerged as a major health problem, because late preterm neonates are at increased risk not only for neonatal morbidities but also for childhood complications as compared with term neonates [8-10].

For pregnant women at risk for early preterm delivery (before 34 weeks of gestation), administration of antenatal corticosteroids is a standard treatment to reduce perinatal mortality and morbidity, especially in terms of respiratory complications [11-13]. Antenatal corticosteroids also can be beneficial for neonates at risk for late preterm birth. Recently, a large randomized controlled trial was conducted to investigate the effectiveness of antenatal corticosteroids in singleton late preterm neonates [14]. This study reported that administration of betamethasone significantly reduced the rate of neonatal respiratory complications in singleton late preterm neonates. Based on this result, guidelines from the National Institute for Health and Care Excellence (NICE), Society for Maternal-Fetal Medicine (SMFM) and American College of Obstetricians and Gynecologists (ACOG) recommend administration of betamethasone for pregnant women at risk of late preterm birth in singleton gestation [15-17].

Some studies reported that antenatal corticosteroids also improved neonatal outcomes in twin preterm births before 34 weeks $[13,18,19]$. Based on these evidences and effectiveness of corticosteroids in preterm singleton pregnancy, ACOG recommends that one course of antenatal corticosteroids should also be used in multifetal pregnant women who are at risk of early preterm birth (before $336 / 7$ weeks of gestation) $[15,20]$. On the contrary, there is a paucity of information regarding the effectiveness of antenatal corticosteroids in twin late preterm birth and the guidelines are not established in this population [15].

The determination of the effectiveness of antenatal corticosteroids in twin late preterm birth is a critical issue with regard to several points. First, the neonatal morbidities in twin preterm neonates may be different from that in singleton preterm neonates [20]. Second, the results of some retrospective studies on the effectiveness of antenatal corticosteroids in preterm twin neonates were conflicting. Some studies reported that the effect of antenatal corticosteroids on neonatal outcomes in twin pregnancy was comparable with that in singleton pregnancy $[13,18,19,21]$. However, there are disagreements as to the effect of antenatal corticosteroids in twin pregnancies $[22,23]$. In addition, a recent report on the use of a corticosteroid in twin late preterm birth showed no reduction in respiratory morbidity [18]. Third, the pharmacokinetics in women with twin pregnancy after administration of betamethasone was different from that in singleton pregnant women, probably resulting in a different effectiveness of corticosteroids between singleton and twin pregnancies [24].

To determine this issue, we will evaluate the efficacy of antenatal corticosteroids in twin pregnancies that are at risk for late preterm birth.

\section{Methods Study design}

In this multicentre, randomized, double-blind placebo-controlled trial, women with a twin pregnancy who are at risk for late preterm birth will be enrolled. Figure 1 shows the model of the study design. After providing written informed consents, the women will be randomly assigned to betamethasone or placebo administration. Except for the administration of antenatal corticosteroids or placebo, the participants will be treated according to obstetric guidelines at the discretion of the attending physician.

\section{Study setting}

This study will be conducted at obstetric departments of two hospitals in South Korea, Seoul National University Hospital and Cheil General Hospital and Women's Healthcare Centre. They are tertiary referral hospitals and the number of twin delivery is approximately 300$400 /$ year in each centre.

\section{Study population}

Women with a twin pregnancy who are at risk for late preterm delivery will be enrolled at $340 / 7$ to $365 / 7$ weeks of gestation. The risk for late preterm delivery includes preterm labour with cervical change, preterm premature rupture of membranes, or maternal-foetal indications that require preterm delivery because of maternal (hypertensive disorder, maternal underlying diseases, etc) or foetal causes (oligohydramnios, foetal growth restriction, etc). After screening for eligibility, information regarding the study will be provided and written informed consent will be obtained. Inclusion criteria and exclusion criteria are shown in Table 1. Dropout criteria include patient's withdrawal of content, occurrence of 
Twin pregnant women (34+0wks to $36+5$ wks of gestation)

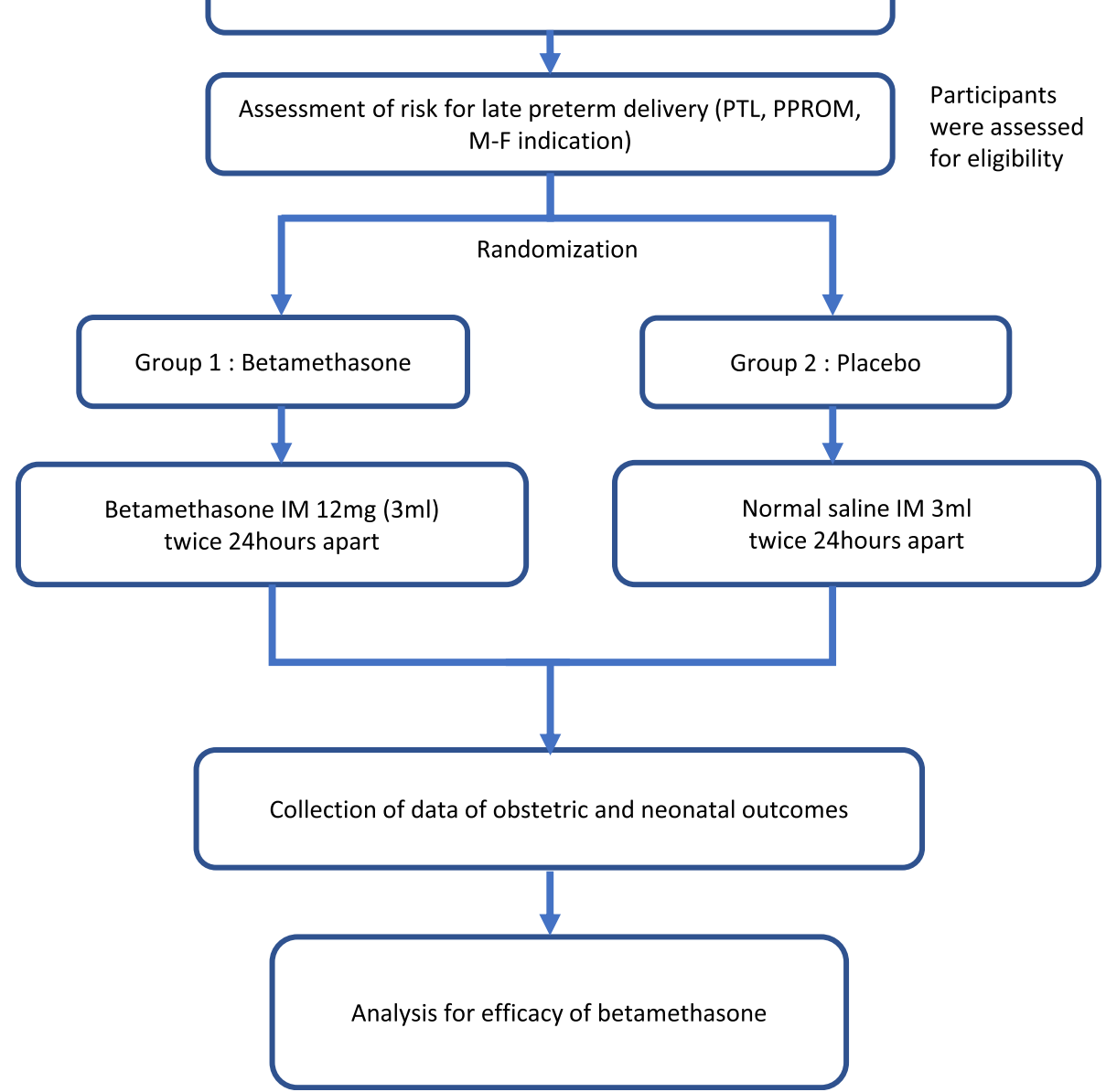

Fig. 1 Study flow chart. PTL, preterm labour; PPROM, preterm premature rupture of membranes; M-F indication, maternal foetal indication; $\mathrm{IM}$, intramuscular

Table 1 Inclusion and exclusion criteria

\begin{tabular}{|c|c|}
\hline Inclusion criteria & Exclusion criteria \\
\hline Age $>20$ years & Gestational age before 34 weeks 0 days or after 36 weeks 6 days \\
\hline $\begin{array}{l}\text { Women with twin pregnancy at } 34 \text { weeks } 0 \text { days to } \\
36 \text { weeks } 5 \text { days of gestation }\end{array}$ & Lethal major foetal anomaly, foetal distress or foetal death in utero \\
\hline At risk for preterm birth & Expected to deliver within $12 \mathrm{~h}$ \\
\hline preterm labour & Advanced cervical dilatation $(\geq 8 \mathrm{~cm})$ in preterm labour \\
\hline PPROM & Active phase labour (cervical dilatation $\geq 4 \mathrm{~cm}$ ) in PPROM \\
\hline \multicolumn{2}{|l|}{ Maternal-foetal indications that need preterm delivery } \\
\hline \multirow[t]{4}{*}{ Availability of written informed consent } & $\begin{array}{l}\text { History of a previous administration of antenatal corticosteroid } \\
\text { within } 1 \text { week }\end{array}$ \\
\hline & Administration of systemic steroid for medical indications \\
\hline & Diagnosis of clinical chorioamnionitis \\
\hline & Contraindication of betamethasone administration \\
\hline
\end{tabular}

Preterm labour is defined as regular uterine contractions with or without the following symptoms; pelvic pressure, backache, increased vaginal discharge, menstrual-like cramps, bleeding/show, cervical changes. Clinical chorioamnionitis is defined as fever $>37.8^{\circ} \mathrm{C}$ and the presence of two more of the following conditions: uterine tenderness, foul-odoured vaginal discharge, maternal leucocytosis $(>1500)$, maternal tachycardia( $>100)$ or foetal tachycardia( $>160)$ PPROM preterm premature rupture of memebrane 
severe adverse reaction, or clinical situation that does not permit continuation of trial protocol at the discretion of the investigators.

\section{Random assignment method}

Enrolled women will be randomly assigned in a 1:1 ratio to antenatal corticosteroids (Group 1) or placebo (Group 2 ). The randomization will be done by a web-based randomization system that is operated by the medical research collaborating center of Seoul National University Hospital. Unblinded researchers will be designated at the beginning of this trial, including an unblinded pharmacist and unblinded investigators, and they will not participate in the subsequent process of data management and data analysis. The unblinded researchers will prepare the antenatal corticosteroids or placebo according to the treatment assignment. Neither the enrolled pregnant women nor the other investigators (except predeterminate unblinded researchers) will be aware of the result of random assignment.

\section{Sample size}

The sample size was calculated to determine how many neonates will be needed to detect a $30 \%$ reduction by antenatal corticosteroids: $20 \%$ in the placebo group versus $14 \%$ in the antenatal corticosteroids group. We estimated the risk of primary outcome in the placebo group as $20 \%$, with a correlation coefficient between co-twins of 0.32, according to our retrospective twin cohort data. We adopted a risk reduction rate of 30\% (from 20 to $14 \%)$, according data in previous study [14]. Assuming $80 \%$ power, a type I error of $5 \%$, and the ratio of $1: 1$ between placebo and antenatal corticosteroids, we determined we would require 1616 neonates (808 twin pregnancies).

\section{Intervention}

The antenatal corticosteroids will be betamethasone sodium phosphate $5.2 \mathrm{mg}$ (betamethasone $4.0 \mathrm{mg}$ ) in 1 ample $(1 \mathrm{~mL})$, produced by Dawon Parm (Korea). Both betamethasone and placebo (normal saline) are colourless liquids. The eligible participants for the inclusion and exclusion criteria will be randomized into two groups: Group 1, antenatal corticosteroids group; Group 2, placebo group. Group 1 consists of pregnant women who will be administered intramuscular betamethasone $12 \mathrm{mg}(3 \mathrm{~mL})$ twice in a 24-h interval. Group 2 will be administered the same amount (3 $\mathrm{mL}$ ) of normal saline twice with the same interval. Once the drug is determined by randomization, the unblinded researchers will prepare and administer betamethasone or placebo to participants.

\section{Study outcomes}

The data on obstetric and neonatal outcome will be gathered. The primary outcome is severe respiratory complications (the use of continuous positive airway pressure or high-flow nasal cannula for at least $12 \mathrm{~h}$, supplemental oxygen administration with a fraction of oxygen 0.3 or more for at least $24 \mathrm{~h}$, mechanical ventilation, or extracorporeal membranes oxygenation) or perinatal death within the first $72 \mathrm{~h}$ of delivery. Secondary outcomes are neonatal mortality and/or other neonatal morbidities (Table 2).

\section{Safety assessment}

The patients will be monitored for symptoms in terms of adverse effects. The physicians will check the patients' vital signs and the occurrence of adverse side effects after injection. Symptoms such as nausea/vomiting, allergic reaction, and local reaction at the injection site will be reported. The administration of the study drug can be interrupted in the occurrence of severe side effects, such as adrenal insufficiency, Cushing's syndrome, and infection. However, serious side effects after antenatal corticosteroids (betamethasone) were not reported in previous studies in pregnant women [14, 25-27].

\section{Analysis}

The efficacy of betamethasone will be assessed by comparing the primary and secondary outcomes of each group. Efficacy analysis will be conducted based on intention-to-treat and per-protocol principle. Categorical variables will be compared by the chi-square or Fisher's exact test. For continuous variables, the Mann-Whitney U test will be used. The analysis will be performed by a generalized estimating equation to consider the possibility of the familial correlation between the neonates from a single mother in twin pregnancies [28]. A $p$ value of less than 0.05 will be considered significant, and relative risks and $95 \%$ confidence intervals will be reported. All analyses will be performed using IBM SPSS Statistics version 23 and $\mathrm{R}$ version 3.5.0 (http://www.r-project.org).

\section{Discussion}

With this study, we intend to evaluate the efficacy of antenatal betamethasone in late preterm delivery among twin pregnancies. In clinical practice, antenatal corticosteroids are used to reduce neonatal morbidity and mortality for preterm birth neonates (before 34 weeks of gestation). Recently, the efficacy of the treatment has also been proved for late preterm singleton neonates, and the therapeutic targets of antenatal corticosteroids has been expanded to late preterm neonates (34 0/7 to 36 6/7 weeks of gestation) as well as neonates born before 34 weeks of gestation. 
Table 2 Primary/Secondary outcomes

\begin{tabular}{|c|c|}
\hline $\begin{array}{l}\text { Primary outcome (within } \\
72 \mathrm{~h} \text { after delivery) }\end{array}$ & $\begin{array}{l}\text { Secondary outcome } \\
\text { (before discharge) }\end{array}$ \\
\hline Severe respiratory morbidities & Mild respiratory morbidities \\
\hline CPAP for $\geq 12$ continuous hours & CPAP for $\geq 2$ continuous hours \\
\hline $\begin{array}{l}\text { High flow nasal cannula for } \geq 12 \\
\text { continuous hours }\end{array}$ & $\begin{array}{l}\text { High flow nasal cannula for } \geq \\
\text { continuous hours }\end{array}$ \\
\hline $\begin{array}{l}\text { Fraction of inspired oxygen of } \\
\geq 0.3 \text { for } \geq 24 \text { continuous hours }\end{array}$ & $\begin{array}{l}\text { Fraction of inspired oxygen of } \\
\geq 0.3 \text { for } \geq 2 \text { continuous hours }\end{array}$ \\
\hline Mechanical ventilation use & Respiratory distress syndrome \\
\hline ECMO use & $\begin{array}{l}\text { Transient tachypnoea of the } \\
\text { newborn }\end{array}$ \\
\hline Stillbirth & Apnoea \\
\hline \multirow[t]{17}{*}{ Neonatal death } & Bronchopulmonary dysplasia \\
\hline & Pneumonia \\
\hline & Surfactant use \\
\hline & Pulmonary air leak \\
\hline & Necrotizing enterocolitis \\
\hline & Intraventricular hemorrhage \\
\hline & Sepsis \\
\hline & Hyperbilirubinemia \\
\hline & Seizures / encephalopathy \\
\hline & Patent ductus arteriosus \\
\hline & Hypoglycaemia \\
\hline & Feeding difficulty \\
\hline & Need for resuscitation at birth \\
\hline & Neonatal death \\
\hline & Maternal complication \\
\hline & Chorioamnionitis \\
\hline & Postpartum endometritis \\
\hline
\end{tabular}

CPAP continuous positive airway pressure, ECMO extracorporeal membranes oxygenation

The efficacy of antenatal corticosteroids in twin neonates with early preterm birth (before 34 weeks of gestation) has been demonstrated in several previous reports. However, there has been no prospective randomized trial on the efficacy of antenatal corticosteroids in twin pregnancies in late preterm birth. In this regard, research on this issue is very crucial in clinical practice.

The results of this study are expected to have great impact on several aspects.

First, the result of this study will provide evidence for clinical guidelines of obstetric care in twin pregnancies. To date, there are few obstetric studies on the effectiveness of antenatal corticosteroids in twin pregnancies, and most of the existing studies have been conducted in singleton pregnancies. Because of this, guidelines about the administration of antenatal corticosteroids in twin pregnancy are based on evidences from singleton pregnancy $[15,20]$.
Second, this study design has methodological strength. This study is a double-blind, randomized controlled study, which provides a high level of evidence. In addition, the objectivity of evaluation variables is expected to yield objective results.

Third, the results of this study will have a significant impact on improving national health and related policies. If the efficacy of antenatal corticosteroids in late preterm neonates is demonstrated, the implementation of guidelines on antenatal corticosteroids in late preterm twin pregnancies will reduce adverse neonatal outcomes and the subsequent burden due to hospitalization of neonates. Otherwise, if the efficacy of antenatal corticosteroids is not proven, it may be the basis for avoiding unnecessary treatment and adverse effects related to corticosteroids.

\section{Abbreviations}

ACOG: American College of Obstetricians and Gynecologists;

IM: Intramuscular; NICE: National Institute for Health and Care Excellence; SMFM: Society for Maternal-Fetal Medicine; USA: United States of America

\section{Acknowledgements}

Not applicable.

\section{Funding}

This study was supported by a grant from the SNUH research fund (2018-1322) and the Korean Society of Maternal Fetal Medicine Research Fund

Funding bodies had no role in the design of the study and collection, analysis, and interpretation of data and in writing the manuscript.

\section{Availability of data and materials}

Not applicable.

\section{Authors' contributions \\ $\mathrm{SH}$ and SML contributed equally as the first authors of this study. JHC and JKJ contributed equally as the corresponding authors of this study. All authors read and approved the final manuscript. SH and SML drafted and revised the manuscript, study design, study protocol, and performed study at respective healthcare center. DWK and SYK contributed study design, study protocol, and performed study at respective healthcare center. JL and JWO contributed study design, and study protocol. SO calculated sample size, and revised the manuscript. CWP and JSP contributed study design, and performed study at respective healthcare center. JHC and JKJ led the committee, coordinated and reviewed this study and made a final approval to publish.}

\section{Ethics approval and consent to participate}

This study is approved by the Institutional Review Board of Seoul National University Hospital (C-1710-063-89), Cheil General Hospital and Women's Healthcare Center (CGH-IRB-2017-42), and Ministry of Food and Drug Safety in Korea, and is registered at ClinicalTrials.gov (NCT03547791). After the participants are provided enough information about the purpose and methods of the research, the written informed consents will be provided as mentioned in methods.

\section{Consent for publication}

Not applicable.

\section{Competing interests}

None of the authors have any conflict of interest.

\section{Publisher's Note}

Springer Nature remains neutral with regard to jurisdictional claims in published maps and institutional affiliations. 


\section{Author details}

'Department of Obstetrics and Gynecology, Seoul National University College of Medicine, Seoul, Republic of Korea. ${ }^{2}$ Department of Obstetrics and Gynecology, Seoul National University Bundang Hospital, Seongnam, Republic of Korea. ${ }^{3}$ Department of Obstetrics and Gynecology, Cheil General Hospital and Women's Healthcare Center, Dankook University College of Medicine, Seoul, South Korea. ${ }^{4}$ Department of Obstetrics and Gynecology, Ajou University Medical School, Suwon, Korea. ${ }^{5}$ Department of Prevention and Management, Inha University Hospital, Incheon, Korea. ${ }^{6}$ School of Medicine, Inha University, Incheon, Korea. ${ }^{7}$ Department of Biostatistics, Seoul Metropolitan Government Seoul National University Boramae Medical Center, Seoul, Korea.

Received: 12 September 2018 Accepted: 4 March 2019

Published online: 03 April 2019

\section{References}

1. Martin JA, Hamilton BE, Osterman MJ. Three decades of twin births in the United States, 1980-2009. NCHS data brief. 2012;80:1-8.

2. Mathews T, MacDorman MF, Thoma ME. Infant mortality statistics from the 2013 period linked birth/infant death data set. 2015;64(9):1-30.

3. Glinianaia S, Rankin J, Wright C. Congenital anomalies in twins: a registerbased study. Hum Reprod. 2008;23(6):1306-11.

4. Sibai BM, Hauth J, Caritis S, Lindheimer MD, MacPherson C, Klebanoff M, et al. Hypertensive disorders in twin versus singleton gestations. American Journal of Obstetrics \& Gynecology. 2000;182(4):938-42.

5. Strauss A, Paek BW, Genzel-Boroviczény O, Schulze A, Janssen U, Hepp H. Multifetal gestation-maternal and perinatal outcome of 112 pregnancies. Fetal Diagn Ther. 2002;17(4):209-17.

6. Martin JA, Hamilton BE, Osterman MJ, Driscoll AK, Mathews TJ. Births: Final data for 2015. National vital statistics reports : from the Centers for Disease Control and Prevention, National Center for Health Statistics, National Vital Statistics System. 2017:66(1):1.

7. Refuerzo JS, Momirova V, Peaceman AM, Sciscione A, Rouse DJ, Caritis SN, et al. Neonatal outcomes in twin pregnancies delivered moderately preterm, late preterm, and term. Am J Perinatol. 2010;27(7):537-42.

8. McIntire DD, Leveno KJ. Neonatal mortality and morbidity rates in late preterm births compared with births at term. Obstet Gynecol. 2008;111(1): 35-41.

9. Raju TN, Higgins RD, Stark AR, Leveno KJ. Optimizing care and outcome for late-preterm (near-term) infants: a summary of the workshop sponsored by the National Institute of Child Health and Human Development. Pediatrics. 2006;118(3):1207-14

10. McGowan JE, Alderdice FA, Holmes VA, Johnston L. Early childhood development of late-preterm infants: a systematic review. Pediatrics. 2011: peds. 2010-2257.

11. Roberts D, Brown J, Medley N, Dalziel SR. Antenatal corticosteroids for accelerating fetal lung maturation for women at risk of preterm birth. Cochrane Libr. 2017;3:CD004454.

12. Gilstrap LC, Christensen R, Clewell WH, D'Alton ME, Davidson EC, Escobedo $M B$, et al. Effect of corticosteroids for fetal maturation on perinata outcomes: $\mathrm{NIH}$ consensus development panel on the effect of corticosteroids for fetal maturation on perinatal outcomes. Jama. 1995; 273(5):413-8.

13. Vaz A, Malheiro MF, Severo M, Rodrigues T, Guimaraes $H$, Montenegro N. Effect of antenatal corticosteroids on morbidity and mortality of preterm singletons and twins. The journal of maternal-fetal \& neonatal medicine : the official journal of the European Association of Perinatal Medicine, the Federation of Asia and Oceania Perinatal Societies, the International Society of Perinatal Obstet. 2018;31(6):754-60.

14. Gyamfi-Bannerman C, Thom EA, Blackwell SC, Tita AT, Reddy UM, Saade GR, et al. Antenatal betamethasone for women at risk for late preterm delivery. N Engl J Med. 2016;374(14):1311-20.

15. Committee Opinion No.677. Antenatal corticosteroid therapy for fetal maturation. Obstet Gynecol. 2016;128(4):e187-94.

16. Implementation of the use of antenatal corticosteroids in the late preterm birth period in women at risk for preterm delivery. Am J Obstet Gynecol 2016:215(2):B13-5.

17. National Collaborating Centre for Ws, Children's H. National Institute for Health and Care Excellence. Clinical guidelines. Preterm labour and birth. In: London: National Institute for health and care excellence (UK) copyright (c)
2015 National Collaborating Centre for Women's and Children's health; 2015.

18. Melamed N, Shah J, Yoon EW, Pelausa E, Lee SK, Shah PS, et al. The role of antenatal corticosteroids in twin pregnancies complicated by preterm birth. Am J Obstet Gynecol. 2016;215(4):482.e1-9.

19. Palas $D$, Ehlinger $V$, Alberge $C$, Truffert $P$, Kayem $G$, Goffinet $F$, et al. Efficacy of antenatal corticosteroids in preterm twins: the EPIPAGE-2 cohort study. BJOG : an international journal of obstetrics and gynaecology. 2018;125(9): 1164-70.

20. Practice Bulletin No. 169. Multifetal gestations: twin, triplet, and higher-order multifetal pregnancies. Obstet Gynecol. 2016;128(4):e131-46.

21. Kuk J-Y, An J-J, Cha H-H, Choi S-J, Vargas JE, S-y O, et al. Optimal time interval between a single course of antenatal corticosteroids and delivery for reduction of respiratory distress syndrome in preterm twins. American Journal of Obstetrics \& Gynecology. 2013;209(3):256. e1-7.

22. Viteri OA, Blackwell SC, Chauhan SP, Refuerzo JS, Pedroza C, Salazar XC, et al. Antenatal corticosteroids for the prevention of respiratory distress syndrome in premature twins. Obstet Gynecol. 2016;128(3):583-91.

23. Choi SJ, Song SE, Seo ES, Oh SY, Kim JH, Roh CR. The effect of single or multiple courses of antenatal corticosteroid therapy on neonatal respiratory distress syndrome in singleton versus twin pregnancies. Aust N Z J Obstet Gynaecol. 2009:49(2):173-9.

24. Ballabh P, Lo E, Kumari J, Cooper T, Zervoudakis I, Auld P, et al. Pharmacokinetics of betamethasone in twin and singleton pregnancy. Clinical Pharmacology \& Therapeutics. 2002;71(1):39-45.

25. Stutchfield P, Whitaker R, Russell I. Antenatal betamethasone and incidence of neonatal respiratory distress after elective caesarean section: pragmatic randomised trial. Bmj. 2005;331(7518):662.

26. Porto AMF, Coutinho IC, Correia JB, Amorim MMR. Effectiveness of antenatal corticosteroids in reducing respiratory disorders in late preterm infants: randomised clinical trial. Bmj. 2011;342:d1696.

27. Balci O, Ozdemir S, Mahmoud AS, Acar A, Colakoglu MC. The effect of antenatal steroids on fetal lung maturation between the 34th and 36th week of pregnancy. Gynecol Obstet Investig. 2010;70(2):95-9.

28. Zeger SL, Liang KY. Longitudinal data analysis for discrete and continuous outcomes. Biometrics. 1986;42(1):121-30.
Ready to submit your research? Choose BMC and benefit from:

- fast, convenient online submission

- thorough peer review by experienced researchers in your field

- rapid publication on acceptance

- support for research data, including large and complex data types

- gold Open Access which fosters wider collaboration and increased citations

- maximum visibility for your research: over $100 \mathrm{M}$ website views per year

At $\mathrm{BMC}$, research is always in progress.

Learn more biomedcentral.com/submissions 